\title{
Comparative Study on the Measurement of Human Thermal Activity
}

\author{
Awais Gul Airij ${ }^{\# 1}$, Rubita Sudirman ${ }^{\#}$, Usman Ullah Sheikh", Teruji Ide ${ }^{+}$, Yusuke Nagata ${ }^{+}$, \\ Kiyotaka Kamata $^{+}$

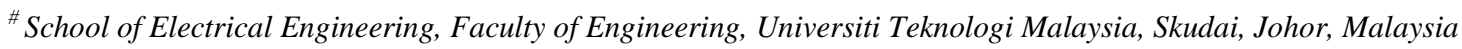 \\ E-mail: *gaawais2@live.utm.my
}

${ }^{+}$National Institute of Technology, Kagoshima College, Kagoshima, Japan

\begin{abstract}
Human physiological signals measurement is the necessity of today's modern world. The physiological signals, including heart rate, skin conductance, temperature, and pupil diameter, are significant indicators of underlying problems or illnesses and aid in indicating the underlying condition non-invasively. This study highlights the importance and needs for only one physiological signal, which is the body temperature as even a minor change in temperature values has a unique effect on the body. Hence, the present study focuses on comparing two well-known temperature sensors, namely DS18B20 and LM35, which are among the top choices for many temperature-based applications. The two sensors are compared in terms of cost, accuracy, temperature range, voltage, output type, implementation, packaging and required signal conditioning circuitry. The sole purpose is to find the adequacy of only one in terms of medical applications. The temperature readings are collected for 15 seconds from 10 participants between the age of 25 - 28 years and the data is sent to a microcontroller, which is Arduino Mega board. The microcontroller board processes the data for noise and artefacts removal and displays the final temperature readings on the serial monitor of Arduino IDE. The results highlight that DS18B20 is more accurate and robust in comparison to LM35, as it has lower fluctuations in the readings and is not affected by user movements. This study will help in the future development of healthcare systems, which may track the user's thermal changes accurately in real-time.
\end{abstract}

Keywords — arduino; healthcare; non-invasive; physiological signals; sensors; temperature.

\section{INTRODUCTION}

Monitoring human physiological signals is state of the art nowadays. A lot of time and money has been put into researching cost-efficient and accurate measurement techniques of human physiological signals. The most commonly measured physiological signals found in other researches are heart rate variation, skin perspiration, pupil diameter, respiration rate and temperature [1], [2]. Each physiological signal has its own importance and provides with a different information that needs to be interpreted and utilized accordingly. These signals represent parameters related to the physiological function of the circulatory, neurological, and respiratory systems and are measured with the help of multiple sensors. However, the present study only focuses on the measurement of only one physiological signal, which is the temperature.

The measurement of warmth and coldness of an object is known as temperature. The well-known scales for temperature measurement are Celsius $\left({ }^{\circ} \mathrm{C}\right)$, Fahrenheit $\left({ }^{\circ} \mathrm{F}\right)$, and Kelvin $\left({ }^{\circ} \mathrm{K}\right)$. The increase or decrease in body temperature is an indication of some underlying problem or infection. The importance of temperature and how it affects the human body functions can be understood by a simple analogy stating as almost everything depends on the variation of temperature. For instance, in an electrical conductor, if the temperature is increased, the resistance also increases. Furthermore, temperature measurement is also necessary for agricultural [3], industrial, and many other engineerings [4]-[8] and medical applications [9], [10]. The thermoregulatory system of the body lies in the hypothalamus, and its role is to maintain the average body temperature, which is in the range of $36.1{ }^{\circ} \mathrm{C}-37.2^{\circ} \mathrm{C}$ [11]. Though this range is affected by the age and the measurement site. Table I shows the different temperature ranges in different human body parts depending on the age of a person.

The humans are homeothermic; therefore, their internal thermoregulatory system maintains the temperature at $37^{\circ} \mathrm{C}$ \pm 1 . Any temperature range below or higher than the normal range will adversely affect a person's health or is an indication of an underlying problem [12]. Both extreme hot and cold temperatures affect an individual adversely and can be fatal at times. 
TABLE I

TEMPERATURE RANGES OF BODY PARTS AT DIFFERENT AGES

\begin{tabular}{|c|c|c|c|c|}
\hline \multirow[b]{2}{*}{ BODY PART } & \multicolumn{4}{|c|}{ TEMPERATURE RANGES IN DIFFERENT AGES $\left({ }^{\circ} \mathrm{C}\right)$} \\
\hline & $\begin{array}{c}0-2 \\
\text { YEARS }\end{array}$ & $\begin{array}{c}3-10 \\
\text { YEARS }\end{array}$ & $\begin{array}{l}11-65 \\
\text { YEARS }\end{array}$ & $\begin{array}{c}>65 \\
\text { YEARS }\end{array}$ \\
\hline ORAL & - & $35.5-37.5$ & $36.4-37.5$ & $35.8-37.0$ \\
\hline RECTAL & $36.6-38.0$ & $36.6-38.0$ & $37.0-38.1$ & $36.1-37.3$ \\
\hline AXILLARY & $34.7-37.3$ & $35.9-36.7$ & $35.2-36.9$ & $35.5-36.3$ \\
\hline EAR & $36.4-38.0$ & $36.1-37.8$ & $35.9-37.6$ & $35.8-37.5$ \\
\hline CORE & $36.4-37.8$ & $36.4-37.8$ & $36.8-37.9$ & $35.9-37.1$ \\
\hline
\end{tabular}

The condition in which the body temperature is less than normal is called hypothermia, and the condition in which the body temperature is higher than normal is called hyperthermia [13]. Table II shows the behaviour of the human body in states of hypothermia and hyperthermia. Many previous studies use temperature readings for different purposes; for instance, a team of researchers in [14] used temperature, heart rate, and skin conductance for the purpose of stress classification.

TABLE II

EFFECTS OF DIFFERENT TEMPERATURES ON THE HUMAN BODY

\begin{tabular}{|c|l|}
\hline $\begin{array}{c}\text { Temperature } \\
\left({ }^{\circ} \mathbf{C}\right)\end{array}$ & \multicolumn{1}{c|}{ Effect } \\
\hline 44 & $\begin{array}{l}\text { Almost death. Sometimes the patient is known to } \\
\text { survive up to } 46.5^{\circ} \mathrm{C}\end{array}$ \\
\hline 43 & $\begin{array}{l}\text { Normally death, brain damage or cardio-respiratory } \\
\text { failure }\end{array}$ \\
\hline $41-42$ & $\begin{array}{l}\text { Fainting, convulsion, tachycardia, confusion, } \\
\text { low/high blood pressure }\end{array}$ \\
\hline $38-40$ & $\begin{array}{l}\text { Severe sweating, dehydration, weakness, vomiting, } \\
\text { dizziness, headache, tachycardia }\end{array}$ \\
\hline 37 & $\begin{array}{l}\text { Normal } \\
\text { Mild or moderate shivering. Mostly normal }\end{array}$ \\
\hline 36 & $\begin{array}{l}\text { Intense shivering, muscle numbness and } \\
\text { bluish/greyness of skin. Heart irritability and } \\
\text { confusion }\end{array}$ \\
\hline $29-33$ & $\begin{array}{l}\text { Severe confusion, sleepiness, progressive loss of } \\
\text { shivering, bradycardia, shallow breathing and } \\
\text { unresponsive to stimuli }\end{array}$ \\
\hline 28 & $\begin{array}{l}\text { Breathing may stop, mostly death but some patients } \\
\text { known to survive at 14.2 }{ }^{\circ} \mathrm{C}\end{array}$ \\
\hline
\end{tabular}

This research focuses on the comparison of two sensors used for measuring thermal changes in the human body, as in many cases, the human body exhibits temperature dependence [11][15]. In this study, two well-known temperature sensors namely: DS18B20 by Dallas Semiconductors and LM35 by Texas Instruments are tested and compared in terms of their characteristics such as ease of applicability, range, cost, operating voltage, performance and accuracy. The comparison is made to identify the most suitable, cost-effective and accurate sensor for medical applications.

The measurement of variation in thermal activity has been observed in many pieces of research using these two sensors, DS18B20 and LM35. The work presented in [13], uses a DS18B20 with AT89S52 microcontroller to develop a wireless temperature sensor network. The work concludes that the system is highly reliable and has a higher precision in the range of $-50^{\circ} \mathrm{C}-120^{\circ} \mathrm{C}$. Another research [16] uses DS18B20 with STC89C51 microcontroller along with a water level sensor to develop a system for control water level and its temperature. In [17], DS18B20 is used with S3C44BOX microcontroller to develop an embedded system for temperature testing. Furthermore, in [18], a wireless temperature measurement system was developed using DS18B20 and 8051 microcontrollers. This research states that the developed system has lower power consumption and is smaller in size. Another temperature measurement system based on FPGA and DS18B20 temperature sensor can be seen in [19], which concludes that the system has higher accuracy and rapid transmission speed. Later, an environmental temperature and humidity wireless monitoring system was developed in [20] using DS18B20.

In [1], LM35 was used in a versatile way as it measured temperature, heart rate, and galvanic skin response in order to determine stress levels of a specific individual which helps in the development of stress detection or stress classification applications. A digital thermometer based on PIC16F77A and LM35 for temperature sensing was developed in [21]. The research states that the developed system can measure up to $+150^{\circ} \mathrm{C}$ with a maximum error of $5.9 \%$. A data acquisition system was built for a cutting tool's temperature measurement in [22]. The system was based on LM35 sensor and an 8051 microcontroller. The research highlights that the proposed system is low-cost, faster and has higher accuracy. Furthermore, in [23], a wireless sensor network system was proposed for elderly care. LM35 was used in this research for temperature sensing and Arduino Mega 2560 as a microcontroller. In the same line of research, an IoT-based health care monitoring system was proposed in [24] which used LM35 and Atmega328 microcontroller.

\section{MATERIALS AND METHODS}

The proposed study compared, LM35 and DS18B20 sensors and the signals were obtained with the help of the Arduino Mega board. The microcontroller collected the data from the two sensors, processed them for noise removal and displayed the final temperature values on the serial monitor of the Arduino IDE. In addition to that, absolute reference temperature values were needed and to obtain that, a standard medical grade temperature measuring equipment was required and for this study, BioLand medical grade thermometer was used as shown in Figure 1. The process flow is shown in Figure 2. The data from the two sensors were collected from ten participants who were in the age range of 25 to 28 years. The two sensors were attached to the fingers of the participants, and they were asked to stay calm with their eyes closed for as error-free as humanly possible data collection. The sensor acquired the values from every participant and recorded for 15 seconds at a 0.5 seconds interval. This way, each sensor provided 30 readings from an individual participant. Both the sensors were integrated with the microcontroller directly without any signal conditioning circuitry, neither in terms of hardware nor software. During the experiment, the reference temperature values were also obtained from each participant using BioLand medical grade digital thermometer. 


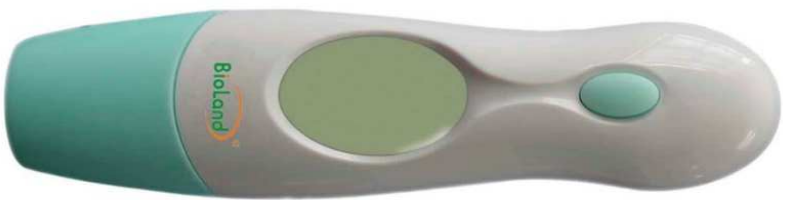

Fig. 1 BioLand medical grade digital thermometer

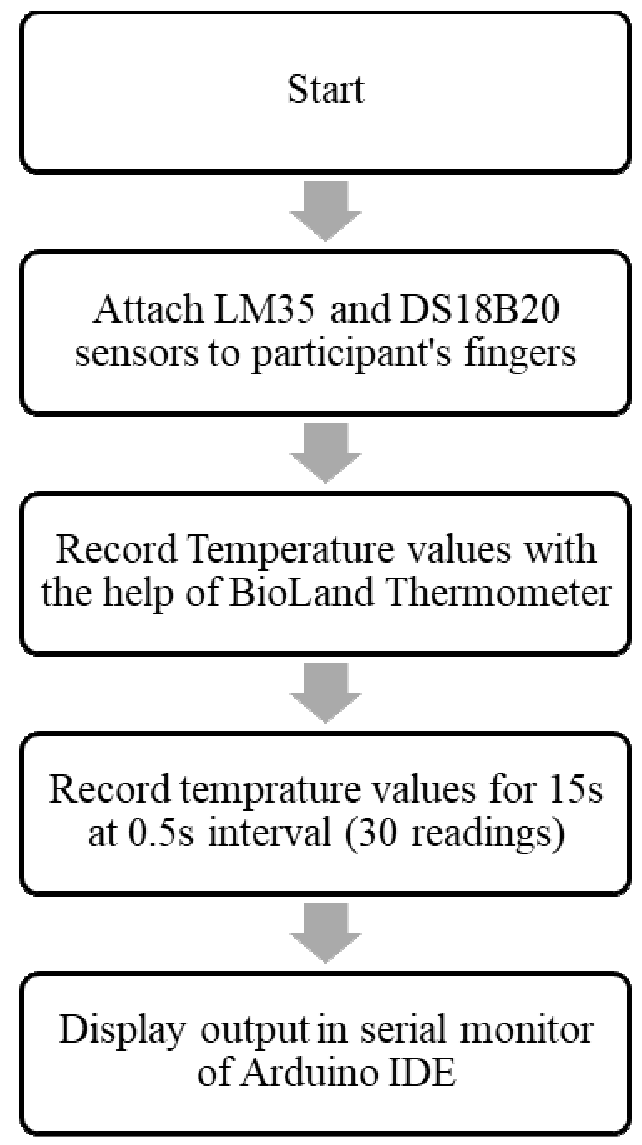

Fig. 2 Process Flow

\section{A. $D S 18 B 20$}

Dallas semiconductors manufacture DS18B20, which is depicted in Figure 3, and the output of it is digital. It is widely known as a one-wire bus interface temperature sensor which is capable of using its data line to derive power as well, known as parasitic power. The working voltage of this sensor is $3.3 \mathrm{~V}$ to $5 \mathrm{~V}$. Each DS18B20 sensor has a unique 64-bit code which allows multiple sensors to function on the same one-wire bus. The temperature range of the sensor is 55 to $+125^{\circ} \mathrm{C}$ and has an accuracy of $\pm 0.1^{\circ} \mathrm{C}$ from $-10^{\circ} \mathrm{C}$ to $+85^{\circ} \mathrm{C}$. It comes in various packages such as TO-92, $\mathrm{SO}$ and $\mu$ SOP. DS18B20 contains an E2ROM and RAM. The ROM is used to store the higher and lower limits of temperature, and it can preserve the values even if the power is cut-off. While the RAM is used for storing temperature values and other parameters. Further detailed information regarding DS18B20 can be obtained from its datasheet.

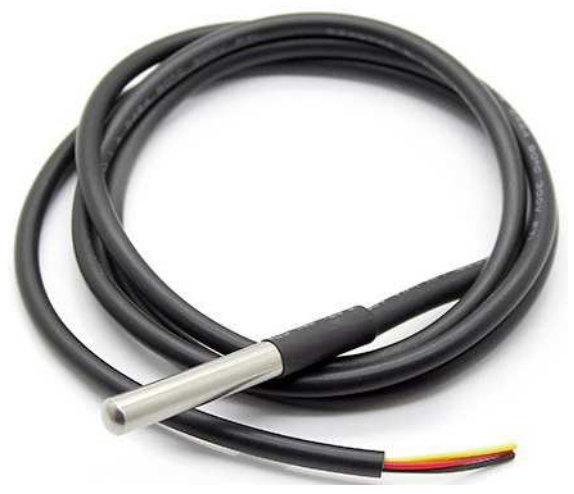

Fig. 3 DS18B20

\section{B. $L M 35$}

Texas Instruments manufacture the LM35 temperature sensor and is shown in Figure 4. These are precision integrated-circuit temperature devices with an output voltage linearly proportional to the centigrade temperature. The working voltage range is $4 \mathrm{~V}$ to $30 \mathrm{~V}$, which is higher than that of DS18B20. The accuracy is $0.5^{\circ} \mathrm{C}$ at $25^{\circ} \mathrm{C}$ and the temperature range of $\mathrm{LM} 35$ is $-55^{\circ} \mathrm{C}$ to $+150^{\circ} \mathrm{C}$. $\mathrm{LM} 35$ comes in various packaging, for instance, TO-CAN, TO-92, TO-220 and SOIC. Further detailed information regarding LM35 can be obtained from its datasheet. LM35 is costeffective, economical, has a wide sensing range and can be externally calibrated. The sensor neither undergoes oxidation nor requires amplification of the output voltage. The summary of characteristics of both the sensors is shown in Table III.

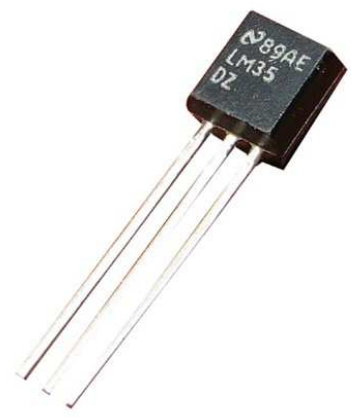

Fig. 4 LM35

TABLE I

CHARACTERISTICS OF DS18B20 AND LM35

\begin{tabular}{|c|c|c|}
\hline Characteristics & DS18B20 & LM35 \\
\hline Package & TO-92, SO, $\mu$ SOP & $\begin{array}{c}\text { TO-46, TO-92, } \\
\text { TO-220, SO }\end{array}$ \\
\hline Working Voltage Range & $3.0-5.5 \mathrm{~V}$ & $4.0-30 \mathrm{~V}$ \\
\hline Accuracy & $\begin{array}{c} \pm 5.0^{\circ} \mathrm{C} \text { from }-10^{\circ} \mathrm{C} \\
\text { to }+85^{\circ} \mathrm{C}\end{array}$ & $0.5^{\circ} \mathrm{C}$ at $+25^{\circ} \mathrm{C}$ \\
\hline Temperature Range & $-55^{\circ} \mathrm{C}$ to $+125^{\circ} \mathrm{C}$ & $-55^{\circ} \mathrm{C}$ to $150^{\circ} \mathrm{C}$ \\
\hline Easy Implementation & $\checkmark$ & $\checkmark$ \\
\hline Require Signal Conditioning & $\mathbf{x}$ & 7.69 \\
\hline $\begin{array}{c}\text { The cost in Malaysian } \\
\text { Ringgit (MYR) }\end{array}$ & 8.49 & Analog \\
\hline \begin{tabular}{c} 
Output Signal Type \\
\hline
\end{tabular} & Digital & $\checkmark$ \\
\hline
\end{tabular}




\section{RESULTS AND DISCUSSION}

The aim of this study was the comparison of two wellknown temperature sensors to identify which is the most suitable one for measuring thermal changes in the human body. The designed equipment incorporating the two temperature sensors DS18B20 (DS) and LM35 (LM), were tested on ten participants and the output temperature readings of all 10 participants along with the reference temperature readings were obtained using the standard thermometer (BL) and are shown in graphical form in Figures 5, 6 and 7. The first three readings of both sensors were neglected in terms of analysis due to sensor initialization. In previous research, LM35 was the choice of various researchers in the health sector, but the results found in this study suggest otherwise. The graphs clearly depict the variations in the temperature readings, which are higher for LM35 and lower for DS18B20. As highlighted in Table II that a minimal change in body temperature can indicate some problems such as hypothermia or hyperthermia. Figure 5 shows the results obtained using the DS18B20 temperature sensor and shows smooth and gradual changes in the temperature readings of each participant. However, the temperature changes recorded using LM35 temperature sensor as depicted in Figure 6, highlight irregular changes.

Furthermore, after performing the statistical analysis, means, errors, mean squared error rates of both the sensors were obtained as shown in Table 4. It can be seen in Table 4, that the mean squared error rate of LM35 is almost twice than that of DS18B20. In addition to that, as the research states that the normal temperature range of a healthy person is in between $35.9^{\circ} \mathrm{C}-37.6^{\circ} \mathrm{C}$. It can be observed that the variation in temperature values of the participants using the LM35 sensor is higher and inaccurate as compared to the temperature variations recorded by the DS18B20 sensor. This also shows that the LM35 sensor has a higher error rate as compared to DS18B20.

The present comparative study is an effort to estimate the accuracy of two low-cost, commercial and non-medical grade temperature sensors for medical applications such as stress detection, stress classification, blood temperature monitoring, digital thermometer, and emotion recognition. The effectiveness of the sensors was measured by comparing the obtained data from the two sensors with a medical-grade thermometer. The need of this study is due to the importance of variations in temperature values of the human body as an indication of some underlying condition, for instance, even a change of $0.1 \mathrm{oC}$ can indicate a problem. As stated in a study [14], that in case of stress arousal, the temperature of the body can rise from $5-15 \mathrm{oC}$ in only a few minutes, however, the exact amount of variation depends on the level of stress experienced by an individual. From the abovementioned results and statistical analysis, it is clear that DS18B20 provides better accuracy as compared to LM35; however, there is still a marginal error in the readings of DS18B20. However, the error rate found in DS18B20 can be easily eliminated with the help of an averaging filter and recording the values at even a smaller interval, for instance, recording temperature readings at $0.1 \mathrm{~s}$ intervals and display the output after averaging ten values, that is at each second. The results of this study show that the DS18B20 temperature sensor is more accurate and suitable for medical applications.
The LM35 sensor has higher fluctuation in comparison to DS18B20 and is also affected by movement. Both of these factors are critical when dealing with humans, especially when the person is already suffering from some ailment. For instance, children suffering from Autism Spectrum Disorder may have difficulties in staying still.

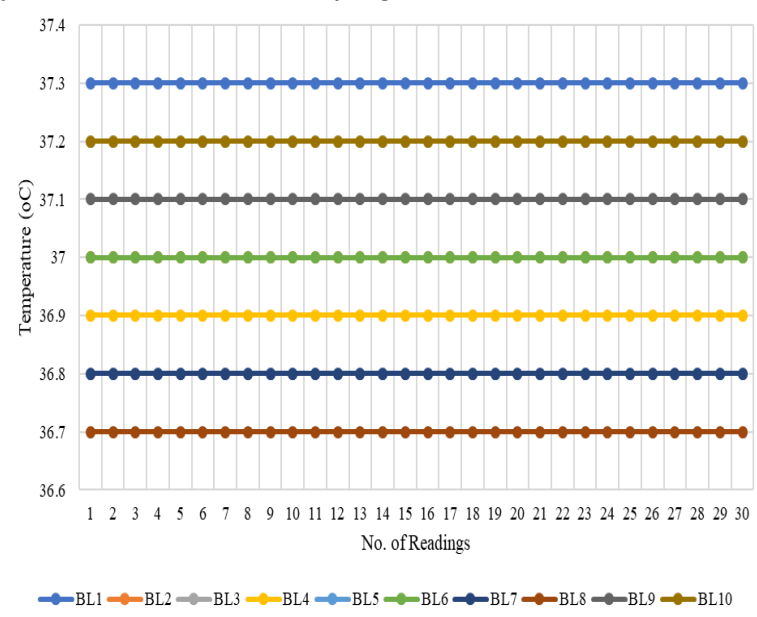

Fig. 5 Results obtained using BioLand digital thermometer

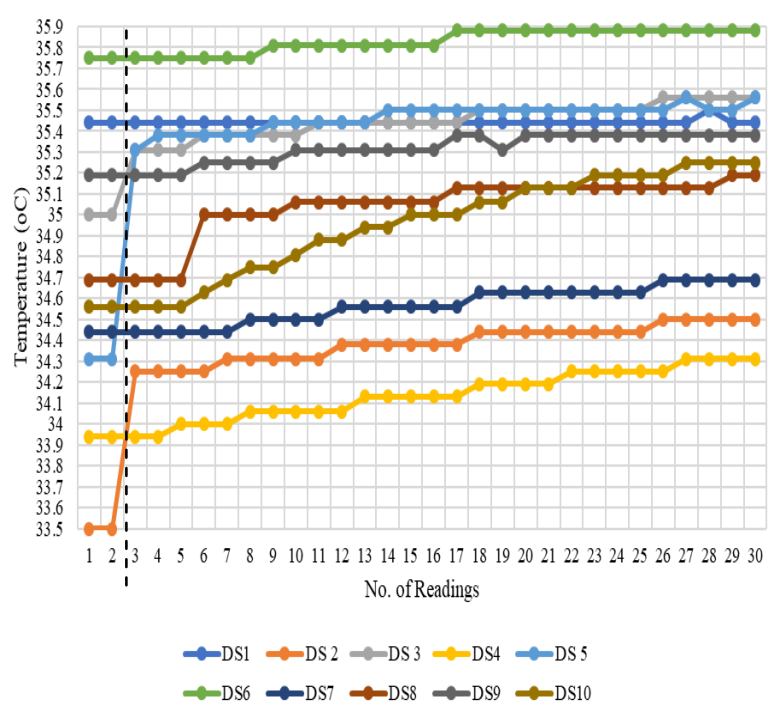

Fig. 6 Results obtained using DS18B20

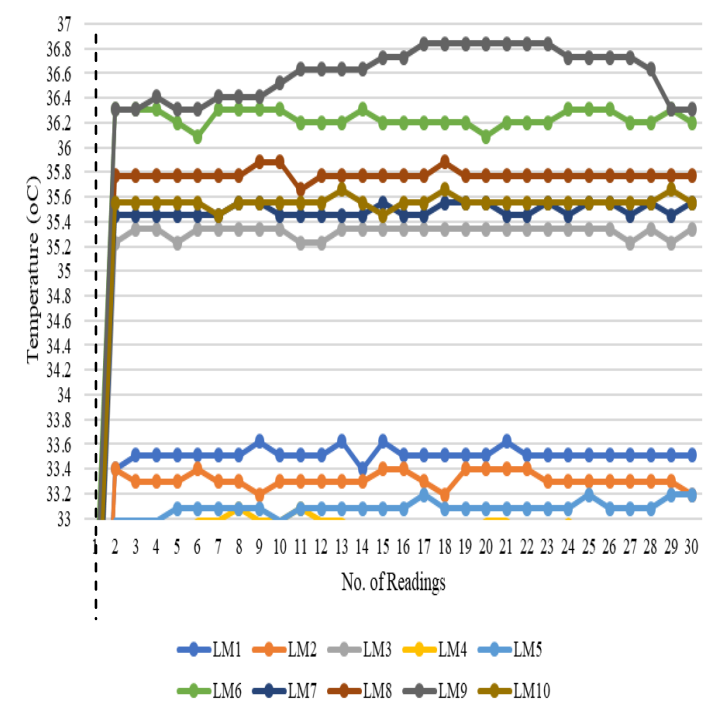

Fig. 7 Results obtained using LM35 
TABLE II

MEAN AND ERROR OF OBTAINED VALUES

\begin{tabular}{|c|c|c|c|c|c|c|c|}
\hline Participants & $\begin{array}{c}\text { Mean } \\
\text { BL }\end{array}$ & $\begin{array}{c}\text { Mean } \\
\text { DS }\end{array}$ & $\begin{array}{c}\text { Mean } \\
\text { LM }\end{array}$ & $\begin{array}{c}\text { Error } \\
\text { DS }\end{array}$ & $\begin{array}{c}\text { Error } \\
\text { LM }\end{array}$ & $\begin{array}{c}\text { MSE } \\
\text { DS }\end{array}$ & $\begin{array}{c}\text { MSE } \\
\text { LM }\end{array}$ \\
\hline 1 & 37.3 & 35.4 & 33.5 & 1.85 & 3.77 & \multirow{10}{*}{3.94} & \multirow{10}{*}{6.67} \\
\hline 2 & 37 & 34.3 & 33.3 & 2.61 & 3.68 & & \\
\hline 3 & 37.2 & 35.4 & 35.3 & 1.74 & 1.88 & & \\
\hline 4 & 36.9 & 34.1 & 32.9 & 2.747 & 3.97 & & \\
\hline 5 & 36.8 & 35.4 & 33.0 & 1.32 & 3.711 & & \\
\hline 6 & 37 & 35.8 & 36.2 & 1.16 & 0.76 & & \\
\hline 7 & 36.8 & 34.5 & 35.4 & 2.22 & 1.30 & & \\
\hline 8 & 36.7 & 35.0 & 35.7 & 1.63 & 0.92 & & \\
\hline 9 & 37.1 & 35.3 & 36.6 & 1.77 & 0.47 & & \\
\hline 10 & 37.2 & 34.9 & 35.5 & 2.21 & 1.64 & & \\
\hline
\end{tabular}

\section{CONCLUSIONS}

This study aimed to compare two temperature sensors, namely LM35 by Texas Instruments and DS18B20 by Dallas Semiconductors to identify the most suitable sensor in terms of low-error rate and a cost-efficient temperature sensor for medical applications. The conclusion can be drawn after testing both the sensors that DS18B20 is more suitable for measuring thermal changes in humans in terms of accuracy and robustness. The conclusion was made based on comparing the outputs of the two sensors with a medicalgrade thermometer. Though LM35 is a little cheaper than DS18B20; however, when dealing with humans, accuracy matters more than the cost.

Moreover, the results also highlighted that increasing or decreasing the recording time has no significant effect on the accuracies of the sensors. In addition to that, this study benefits the future researchers who may use the DS18B20 sensor for medical applications, for instance, stress detection system, emotion recognition system, telehealth systems, and other temperature-dependent systems. In future research, more commercially available low-cost sensors can be compared along with these two sensors such as Grove Temperature sensor, TMP007 contactless infrared thermopile temperature sensor, and DHT22 temperature sensor. In addition to that, commercially available heart rate sensors and skin perspiration sensors can also be compared to find the best fit for medical applications.

\section{ACKNOWLEDGEMENT}

The authors would like to express heartfelt thanks to Ministry of Science, Technology, and Innovation - Escience Fund for supporting and funding this research under grant number 4 S094. The authors would also like to thank the Ministry of Education Malaysia and Universiti Teknologi Malaysia (UTM) for their support under the Research
University Grant (GUP), grant numbers Q.J130000.2523.19H61.

\section{REFERENCES}

[1] A. G. Airij, R. Sudirman, and U. U. Sheikh, "GSM and GPS based real-time remote physiological signals monitoring and stress levels classification," 2nd Int. Conf. BioSignal Anal. Process. Syst. ICBAPS 2018, pp. 130-135, 2018.

[2] A. Gul Airij, R. Bakhteri, and M. Khalil-Hani, "Smart wearable stress monitoring device for autistic children," J. Teknol., vol. 78, no. 7-5, 2016.

[3] B. Kim and S. Oh, "Design of Temperature and Humidity Integrated Sensor Module for Farm Management," Adv. Sci. Lett., vol. 22, no. 11, pp. 3232-3236, Nov. 2016.

[4] M. Farhat, M. Abdul-Niby, M. Abdullah, and A. Nazzal, "A Low Cost Automated Weather Station for Real Time Local Measurements A Low Cost Automated Weather Station for Real Time Local Measurements," Technol. Appl. Sci. Res., vol. 7, no. 3, pp. 1615$1618,2017$.

[5] A. H. Buller, "Flexural Strength of Reinforced Concrete RAC Beams Exposed to 6-hour Fire - Part 2 : Rich Mix," vol. 9, no. 1, pp. 38143817, 2019.

[6] A. Q. Jakhrani, “Appraisal of Climatic Conditions for Potential Solar Energy Applications in Nawabshah and Quetta Cities," vol. 9, no. 1, pp. 3711-3714, 2019.

[7] E. Alizadeh, "An Investigation of the Effect of Ventilation Inlet and Outlet Arrangement on Heat Concentration in a Ship Engine Room," vol. 7, no. 5, pp. 1996-2004, 2017.

[8] M. Z. Abbasi, "An Investigation of Temperature and Wind Impact on ACSR Transmission Line Sag and Tension," vol. 8, no. 3, pp. 30093012, 2018

[9] N. Kumar, "IoT architecture and system design for healthcare systems," Proc. 2017 Int. Conf. Smart Technol. Smart Nation SmartTechCon 2017, pp. 1118-1123, 2018.

[10] J. Wang, "Design intelligent temperature monitoring system based on DSP," Proc. 2012 4th Int. Conf. Intell. Human-Machine Syst. Cybern. IHMSC 2012, vol. 2, pp. 234-237, 2012.

[11] T. H. Y. Ling, L. J. Wong, J. E. H. Tan, and K. Y. Kiu, "Nonintrusive Human Body Temperature Acquisition and Monitoring System," Proc. - Int. Conf. Intell. Syst. Model. Simulation, ISMS, vol. 2015-Octob, pp. 16-20, 2015.

[12] A. Schneider and S. Breitner, "Temperature effects on health current findings and future implications.," EBioMedicine, vol. 6, pp. 29-30, 2016.

[13] J. K. N. Mazima, M. Kisangiri, and D. Machuve, "Design of Low Cost Blood Pressure and Body Temperature interface," Int. J. Emerg. Sci. Eng., vol. 1, no. 10, pp. 109-114, 2013.

[14] V. J. Madhuri, M. R. Mohan, and R. Kaavya, "Stress Management Using Artificial Intelligence," 2013 Third Int. Conf. Adv. Comput. Commun., pp. 54-57, 2013.

[15] S. Sumriddetchkajorn and K. Chaitavon, "Field test studies of our infrared-based human temperature screening system embedded with a parallel measurement approach," Infrared Phys. Technol., vol. 52, no. 4, pp. 119-123, 2009.

[16] Z. Jianping, "On-line measure system of the temperature in the synthetic ammonia tower based on the DS18B20 temperature sensor," 2009 Int. Conf. Meas. Technol. Mechatronics Autom. ICMTMA 2009, vol. 1, pp. 102-104, 2009.

[17] F. Xiong, "Wireless temperature sensor network based on DS18B20, CC2420, MCU AT89S52," Proc. 2015 IEEE Int. Conf. Commun. Softw. Networks, ICCSN 2015, pp. 294-298, 2015.

[18] B. Huang, J. Lei, and Y. Bo, "The reading data error analysis of 1wire bus digital temperature sensor DS18B20," Proc. 2012 Int. Conf. Model. Identif. Control. ICMIC 2012, pp. 433-436, 2012.

[19] P. Li, Y. Zhou, X. Zeng, and T. F. Yang, "A design of the temperature test system based on grouping DS18B20," ICIEA 2007 2007 Second IEEE Conf. Ind. Electron. Appl., pp. 188-191, 2007.

[20] S. Hongyao, F. U. Jianzhong, and C. Zichen, "Embedded system of temperature testing Based on Ds18B20," in International Technology and Innovation Conference, 2006, pp. 2223-2226.

[21] K. Mahmud, M. S. Alam, and R. Ghosh, "Design of digital thermometer based on PIC16F77A single chip microcontroller," in 2013 3rd International Conference on Consumer Electronics, Communications and Networks, 2013, pp. 246-249. 
[22] S. Arunaganesan, J. Adhavan, G. S. Reddy, and M. Venkatesan, "Data acquisition system based on 8051 microcontroller for cutting tool temperature measurement," 2013 IEEE Int. Conf. Comput. Intell. Comput. Res. IEEE ICCIC 2013, pp. 1-4, 2013.

[23] M. Tariq, M. Niaz, M. Tahzeeb, S. Kamran, and M. Wasim, "Wireless Sensor Network to Monitoring the Patient Health System
Internet of things (IoT) based using ZigBee," Int. J. Comput. Appl., vol. 182 , no. 20 , pp. 17-22, 2018.

[24] S. Chaudhury, D. Paul, R. Mukherjee, and S. Haldar, "Internet of Thing based healthcare monitoring system," in 2017 8th Annual Industrial Automation and Electromechanical Engineering Conference (IEMECON), 2017, pp. 346-349. 